\title{
Weight Fluctuation
}

National Cancer Institute

\section{Source}

National Cancer Institute. Weight Fluctuation. NCI Thesaurus. Code C50810.

Repetitive loss and regain of body weight. 